\title{
Optimizing alcohol screening according to DSM-5 severity by adaptive testing using the AUDIT
}

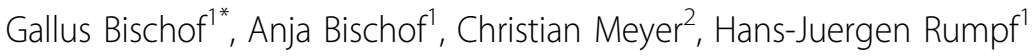 \\ From INEBRIA 12th Congress, \\ Atlanda, GA, USA. 24-25 September 2015
}

\section{Background}

Due to unsatisfactory results of alcohol-related SBI in patients with severe Alcohol Use Disorders (AUDs), many studies aim to exclude severe cases by defining a cut-off in the upper range of the Alcohol Use Disorders Identification Test AUDIT. However, research focusing on optimal cut-offs is still insufficient. In addition, cutoff values of the AUDIT for DSM-5 substance use disorder criteria have not been analysed so far.

\section{Material and methods}

Data were collected in a general population sample $(\mathrm{n}=4.075)$. Alcohol consumption and alcohol use disorders were assessed using the Munich Composite International Diagnostic Inventory (M-CIDI) in all participants as the gold standard. Participants were then grouped according to M-CIDI into individuals without alcohol-related risks, at-risk consumers without AUDs and individuals with alcohol use disorders according to DSM-5. Alcohol Use data was dichotomized into belonging to the target group of SBI (at-risk drinking and/or mild or moderate AUD) vs. not belonging to the target group (unrisky drinking pattern or severe AUD).

\section{Results}

In both samples, the best inclusion criteria on the lower end was a cut-off value of 5 points in the AUDIT-C. Combining AUDIT-C with 5 points and the remaining AUDIT-items with a cut-off of maximum 6 points in order to exclude severe AUDs yielded the best performance. The Area under the Curve (AUC) for adaptive testing using these cut-off values was significantly better than using a simple AUDIT in-/exclusion rule of 5 and 11 points (AUC .77 vs. .73, $\mathrm{p}=.01$ ).

\footnotetext{
* Correspondence: gallus.bischof@uksh.de

'Dpt. of Psychiatry, University of Luebeck, Luebeck, Germany

Full list of author information is available at the end of the article
}

\section{Conclusions}

Data suggest that adaptive screening can improve the identification of individuals with at risk drinking and non-severe AUDs. Further research on the performance of adaptive screening in trials on SBI is warranted.

\section{Acknowledgements}

The data described in this paper are part of the project "Transitions in Alcohol Consumption and Smoking (TACOS)" funded by the German Federal Ministry of Education, Science, Research and Technology (grant no. 01 EB 9406).

\section{Authors' details}

'Dpt. of Psychiatry, University of Luebeck, Luebeck, Germany. ${ }^{2}$ Institute of Epidemiology and Social Medicine, University of Greifswald, Greifswald, Germany.

Published: 24 September 2015

doi:10.1186/1940-0640-10-S2-08

Cite this article as: Bischof et al: Optimizing alcohol screening according to DSM-5 severity by adaptive testing using the AUDIT. Addiction Science \& Clinical Practice 2015 10(Suppl 2):O8.

\section{Submit your next manuscript to BioMed Central and take full advantage of: \\ - Convenient online submission \\ - Thorough peer review \\ - No space constraints or color figure charges \\ - Immediate publication on acceptance \\ - Inclusion in PubMed, CAS, Scopus and Google Scholar \\ - Research which is freely available for redistribution

C Biomed Central

(c) 2015 Bischof et al. This is an Open Access article distributed under the terms of the Creative Commons Attribution License (http:// creativecommons.org/licenses/by/4.0), which permits unrestricted use, distribution, and reproduction in any medium, provided the original work is properly cited. The Creative Commons Public Domain Dedication waiver (http://creativecommons.org/publicdomain/ zero/1.0/) applies to the data made available in this article, unless otherwise stated. 